\title{
Students' Self Revision in Essay Writing
}

\author{
Mohammad Febryanto \\ English Department, Politeknik Negeri Bandung, Indonesia \\ Email: m.febryanto@polban.ac.id
}

\begin{abstract}
This study investigates self-revision in essay writing conducted by 6 students. The analysis is based ondetermining common revised errors. The data have been reduced based on Language Related Episodes (LREs). The result shows that there are revision consisting of 1 change in punctuation both in first and second essay, 5 changes spelling in first essay, 19 changes vocabulary in the first essay and 6 changes in second essay, 25 changes in word form correction in the first essay and 27 changes in the second essay, and there are 19 changes in sentence level the first essay and 13 changes in the second one. This indicates that the selfrevision is predominantly focused onthe word level changes particularly in morphology.
\end{abstract}

Keywords: self-revision, common revised errors, Language Related Episodes (LREs),

\section{Introduction}

In the last decade, the issue of learning based on revision in writing has attracted a number of researchers such as DeJong and Schellens (1997), Bisaillon (2007), Fitzgerald and Stamm (1990), Crawford and Knoth (2008), Suzuki (2008), Chase (2012), Yang and Meng (2013), Wingard abd Geosit (2014) and Wang (2015). There are common results of these researches that suggest the effectiveness of language learning in writing skill through revision since it enables both the teachers and learners to specify the learning needs of specific problems through error-indexing reference. This also shows that learning writing skill in EFL is regarded as the process that includes the most language aspects such as grammar, morphology, text structure and others. Thus, this study attempts to investigate what aspects are mostly concerned by the EFL learners in the Indonesian setting through self-revision strategy.

In EFL context, creating good writing in English is not easy for EFL students. This means they have to work hard to write an English text since English written form has different system with their native language. Moreover, in writing, putting an idea or opinion is not easy. This means students must consider the process of writing. The process of writing is important for beginner or EFL students. As Brown (2007) states that the process gives learners advantages as the language creator to focus on the content and message. In addition, Shih (1986) mentions that the approach, focusing on the process and leading to the final product, helps students to understand their own writing process, enables learners to write, rewrite, and put the importance of revision process. This willfinally give the learner a chance to write what they want to say.

Similarly Harmer (2007) states that the process of writing includes several stages, namely, pre-writing, editing, re-drafting and producing. Furthermore, Hyland (2003) defines the process of writing as planning, drafting, revising, editing and publishing. In the process, the students will think out the procedure in creating good piece of writing. In other words, the 
stages will guide the students what they have to do first when they want to write. The prewriting process, as the first stage, helps the students in generating the ideas - brainstorm the possible topic for them to develop - and creating outline. The next stage is drafting. This stage enhance the students to develop the outline into draft. Revising and editing, as the third stage, always go hand in hand in polishing the quality of the text before the text is published.

Revision, as one of the stages in writing process, is aimed to see again the draft in order to improve the draft better. Tynjala, Mason and Lonka (2001) mention that revising is aimed to improve the quality of the text by involving re-read again to the text. The activities that can be done in revising areadding and or removing ideas, giving more detail or specific support, removing irrelevant sentences, re-arranging the ideas. The other activities in revising can based on Language Related Episodes (LREs). The students will consciously figure out the meaning of a linguistic topic, a spelling of the word, a grammatical aspect, and the implicitly or explicitly the use of a word, form or structure (Lesser, 2004), (Swain \& Lapkin, 1998);(Williams, 1999).

There are several research have been conducted related to revision. A research from Crawford, Lloyd, and Knoth (2008) showsthat revision taxonomy was used to score the state writing test to find type and quality of revisions that made by students between first and final. The revisions categories are unit (e.g., word, phrase, sentence), and type (e.g., addition, substitution, spelling). First, in unit,Grades 5 and 8 maderevisions in word. It was the most prevalent (approximately 40\%). Second, for type, substitutions was revisedapproximately $45 \%$ in all revisions, while additions became the most positive impact on students' final drafts.

Another study conducted by Suzuki (2008). In the research, there were 24 Japanese university students' being asked to doself-revision and peer revision toward their EFL writing. The study categorized the changes into (a) think-aloud of participants' self-revisions, (b) transcriptions of their discussions, and (c) changes students made to their written texts. Other data was from interviews with individual participants. There were more episodes(682 episodes) during peer revisions than during self-revisions (522 episodes). In addition there were 287 text changes in self revision and 166 text changes as occurred in peer revisions. Peer revisions provided more meta-talk than self-revisions. Self-revision tended to involve based on individual knowledge such as word choices or grammar.

The concept of this researchis combination of the research conducted by Suzuki (2000) and Crawford, Lloyd, and Knoth (2008). The research conducted by Suzuki is more similar. In addition, this research has investigated the focus of revision that was conducted by the students when they see again their essay. Hopefully this research can give contribution to English study program especially in teaching writing.

\section{Method}

A descriptive has served as the method of this research to show detail contextualized picture of phenomenon. There were 6 students of English study program as the correspondents in the research. They represented three different levels. The first was the lower level consisting of the score range between 50-69.9, the second was middle level 70-79.9, and last was higher level 80-100.Each of the levels was represented by 2 students. 
The data was gathered from students' essay. This means that this research used document as the source of the data. There were 12 essays each of which consisted of five paragraphs. The first essay was based on their preference, and the second was division essay. In conducting the revision process, the students were given the guideline to help them inrevising their work.

The data had been analyzed by using the Miles and Huberman method including inductive data reduction, data display, drawing conclusion/verification. Reducing was conducted to select and simplify the data related to the changes that the students made in revising their writing. In this step, the data of the students' revision were selected and categorized based on Language Related Episodes (LREs) that promote by(Lesser, 2004), (Swain \& Lapkin, 1998); (Williams, 1999). Next step was displaying the data. The data were presented in term of text and table. This was done to help the readers in understanding the data easily. The last step was drawing conclusion/verification. The interpretation to the data that collected from the document before stating the conclusion.

\section{Findings}

The table below shows the data related to the types of text change for the two essays of the whole participants. For the first essay, in word level there are 5 text changes in spelling, 19 text changes in vocabulary, 25 text changes in word form correction, and 1 text changes in punctuation. In sentence level, there are 19 text changes in change length of sentences either in adding or deleting words. For the second essay, in word level there are 6 text changes in vocabulary, 27 text changes in word form correction, and 1 text changes in punctuation. In sentence level there are 13 text changes in change length of sentences both adding and deleting word.

Table 1 Types of Text Change

\begin{tabular}{|l|l|c|c|}
\hline \multicolumn{2}{|c|}{ Types of text change } & $\begin{array}{c}1^{\text {st }} \\
\text { Essay }\end{array}$ & $\begin{array}{c}\mathbf{2}^{\text {nd }} \\
\text { Essay }\end{array}$ \\
\hline \multirow{3}{*}{ Word level changes } & Spelling & 5 & - \\
\cline { 2 - 4 } & Vocabulary & 19 & 6 \\
\cline { 2 - 4 } & Word form correction & 25 & 27 \\
\cline { 2 - 4 } & Punctuation & 1 & 1 \\
\hline $\begin{array}{l}\text { Sentence level } \\
\text { changes }\end{array}$ & $\begin{array}{l}\text { Change length of sentence by adding or deleting } \\
\text { words }\end{array}$ & 19 & 13 \\
\hline
\end{tabular}

\section{Changes in word level}

This section provides the example of word level changes for the first essay and the second essay. In spelling changes, the text change was made by the low level achiever. The example of the of the changes are "so the wather can understand easily...". In the first draft the participant wrote 'wather' then in revision process, the participant corrected into 'watcher'. The other example of text change in spelling is "...the starting and ending point of yor video". There is missing letter in the word 'yor', so the participant made a correction in that word.

The next example is vocabulary changes. Vocabulary text changes can be found in every level of the achievers. The example of vocabulary changes is "to provide a good video you need to 
edit.." the word provide was change into "create'. Another example is "Second, you must groom your cat's fur often", the respondent change the word 'groom' into 'brush'. The respondent thinks that the word brush is more relevant to the context rather than groom.

Based on the table above, word form correction can be found in the first essay and the second one. This is the example of high level achiever "Love can make you excited but sometimes it can drives you crazy too". The participant changed the word 'drives' into drive'. The participant realizes that she made a mistake, so she corrected it. Another example is from middle level achiever. The participant realized that she made a mistake in subject and verb agreement. This is the extract "Almost everyone have a problem with their bad habits". Then she changed 'have' into 'has'. This is the example of word form correction from low middle, "A competitive game in progress is, surely a fascinating treat to watch". The participant made correction in restructuring the sentence "A competitive game in progress is.." become "A competitive game is in progress. Besides, he changed the active voice into passive voice. As the evidence "... surely a fascinating treat to watch" become "surely a fascinating treat to be watched".

The number of changes in punctuation is not significant. This shows that the participants aware to the use of punctuation in their writing. The data that can be found was the change in comma. The sample is "Unfortunately I still can't fight of eating unhealthy food habit". The participant thinks that the sentence needs comma after the word 'unfortunately', so she puts comma after the word.

\section{Changes in sentence level}

The respondents also made the changes in sentence level. This means that they paid attention to the clarity of the idea. The example of changes conducted by high level is "I will tell you some ways to increase the chances your crush will turn into something more. The participant deletes the last sentence because she thinks that last sentence is already represented by the previous sentence. Another example from high level is adding a sentence. The original she wrote "First, you need to take your cat to a vet for annual check-ups." During revision process, she adds a sentence to make the idea become clearer. This revision result "First, You need to keep your cat healthy. You can take your cat to a vet for annual check-ups."

The middle level also made changes in level sentence. The first example is "it makes people reach some important places such as office, mall, recreation place, etc". The respondent deletes "such as office, mall, recreation place, etc." and replace by "that they usually go". The other example is "You only need a computer connected to internet and you will just wait for your thing to be delivered." The respondent added another idea that is "that you bought", so the complete sentence become "You only need a computer connected to internet and you will just wait for your thing that you bought to be delivered".

This is the example of revision that conducted by low level. In draft, the respondent wrote "the old method one goalie, two full backs, and three half backs, and five forwards made the lineup. The centre-half had the pivotal role." The sentence is not clear, but he made revision by changes the sentence become "It contains of 2 wings backs, 2 centre back, 2 wing backs, 2 centre midfielders, 2 strikers. And it has formation, the most popular formation now are 42-3-1, 4-1-4-1, and 4-3-3." Another example, he wrote "The duration of the game in the 
international contest is a period of 90 minutes". He deleted "of the game in the international contest" and "a period of", so the sentence becomes "The duration is a 90 minutes".

\section{Discussion}

The revision that the participants did shows that they need a process in writing. They cannot make a good essay only in one time. After they finished write a draft, they need to read again their work to make sure that they already stated the idea or information clearly. As mention by (Brown, 2001) that revising the core in writing process, therefore students have to read again their work before they publish it.

The findings show that the participants have the awareness of what they have to do in revising their work. In revising process the participants was trying to give the attention to their work in term of linguistic form and the context. They were concerned about the meaning of a linguistic item, correctness of the spelling of the word, the correctness of a grammatical form, and the implicit or explicit messages in correcting their own or another's usage of a word, form or structure (Leeser, 2004, Swain \& Lapkin, 1998; Williams, 1999).

In word level, the participants made changes related to punctuation, spelling, vocabulary and word form corrections. Punctuation is not really the problem for the participants. This means that they already know how to apply punctuation in their writing. Apart from that, especially the low level correspondents, they made mistake in spelling the correct word but they can are aware that the way they write is incorrect. In the essays, the word choice is also important because different context will have their own terms. The high and middle participants were concerned about the appropriate word to be used. This is indicated by the fact that they altered the inappropriate words with the correct ones.

In general, word form correction is more dominant than the other types of correction. As the data show that there are 25 changes in the first essay and 27 changes in the second essay. The participants, in the revision process, made changes which relate to the subject-verb agreement, tenses, article, pluralization (Suzuki, 2008). This means that they are trying to avoid grammatical mistake.

In addition the sentence level has also become the participants' attention in revising their writing. The data show that there are 19 changes in the first essay and 13 changes in the second one. They can identify that their idea is not clear therefore they add and or delete word to make it clear. Similarly, the participants made changes in the term of sentence type. They changed the active sentences into passive, simple sentence into complex sentence and vice versa.

\section{Conclusion}

The result of this study shows that the focus of revision conducted by the participants is on the word level such as punctuation, spelling, and vocabulary; and particularly in the word form correction. Word form correction takes the highest concern when the students re-read again their essays. Basically the participants have been aware that in writing they have to go through the process to make their writing better. This indicates that they were already able to revise their own work. This means that the participants have potential to produce good writing. However, they have to learn more about the aspects in revising their work. This research can generate a hypothesis for further research based on quantitative approach to supply proof 
related to the tendency of vocabulary use as clear indication of the students' knowledge in the language. This means that sufficient samples will be then required to represent the validity of the result.

\section{References}

Bisaillon, J. (2007). ERIC. Retrieved from http://eric.ed.gov: http://dx.doi.org/10.1177/0741088307305977

Brown, H. D. (2001). Teaching by Principles: An Interactive Approach to Language Pedagoy, Second Edition. New York: Addison Wesley Longman, Inc.

Chase, M. (2012). ERIC. Retrieved from https://eric.ed.gov/: http://www.ncte.org/journals/la/issues/v89-3

Crawford, L., Lloyd, S., \& Knoth, K. (2008). ERIC . Retrieved from https://eric.ed.gov/: http://dx.doi.org/10.1177/1534508407311403

DeJong, M., \& Jan Schellens, P. (1997, Oktober). ERIC. Retrieved from https://eric.ed.gov: https://eric.ed.gov/?q=Schellens+and+Dejong++\&id=EJ629177

Fitzgerald, J., \& Stamm, C. (1990, November). ERIC. Retrieved from https://eric.ed.gov/: https://eric.ed.gov/?q=fitzgerald+and+stamm\&id=ED331052

Harmer, J. (2007). The Practice of English Language Teaching 4th Edition. Essex: Pearson Education Limited.

Hyland, K. (2003). Second Language Writing. Cambridge: Cambridge University Press.

Lesser, M. J. (2004). sagepublication. Retrieved from http://tr.sagepub.com/content/8/1/55: DOI: 10.1191/13621688041r134oa

MacArthur, C. A. (2007). Best Practices in Teaching Evaluation and Revision. In S. Graham, C. A. MacArthur, \& J. Fitzgerald, Best Practices in Writing Instruction (pp. 141-162). New York: The Guilford Press.

Shields, M. (2010). Essay Writing: A Student's Guide. London: Sage Publications Inc.

Suzuki, M. (2008). Japanese Learners' Self Revision and Peer Revisions of Their Wriiten Composition in English. TESOL Quartely, Vo. 42, No. 2, 209-233.

Swain, M., \& Lapkin, M. (1998). Interaction and second language learning: Two adolescent French immersion students working together. Modern Language Journal, 82, 320-337.

Wang, W. (2015). ERIC. Retrieved from https://eric.ed.gov/: https://eric.ed.gov/?q=students+revision+\&id=EJ1075254

Williams, J. (1999). Learner-Generated Attention to Form. Language Learning, 51, 303-346.

Wingard, J., \& Geosits, A. (2014, April 6). ERIC. Retrieved from https://eric.ed.gov/: http://wac.colostate.edu/atd/articles/wingard_geosits2014.cfm

Yang, Y.-F., \& Meng, W.-T. (2013). ERIC. Retrieved from https://eric.ed.gov/: http://llt.msu.edu/issues/june2013/yangmeng.pdf 